\title{
Individual and collective problem-solving in a foraging context in the leaf-cutting ant Atta colombica
}

\author{
Audrey Dussutour $\cdot$ Jean-Louis Deneubourg $\cdot$ \\ Samuel Beshers • Vincent Fourcassié
}

Received: 3 July 2007 / Revised: 26 May 2008 / Accepted: 26 May 2008 / Published online: 17 June 2008

(C) Springer-Verlag 2008

\begin{abstract}
In this paper we investigate the flexibility of foraging behavior in the leaf-cutting ant Atta colombica, both at the individual and collective levels, following a change in the physical properties of their environment. We studied in laboratory conditions the changes occurring in foraging behavior when a height constraint was placed 1 $\mathrm{cm}$ above part of the trail linking the nest to the foraging area. We found that the size and shape of the fragments of foraging material brought back to the nest were significantly modified when the constraint was placed on the trail: independent of their size, forager ants cut smaller and rounder fragments in the presence of a height constraint than in its absence. This size adjustment does not require any direct sensory feedback because it occurred when the ants cut fragments in the foraging area; no further cutting was done when they encountered the constraint. This points to the existence of a template that ants store and use as a
\end{abstract}

A. Dussutour · V. Fourcassié

Centre de Recherches sur la Cognition animale,

UMRCNRS 5169, Université Paul Sabatier,

118 route de Narbonne, 31062 Toulouse Cedex 4, France

A. Dussutour · J.-L. Deneubourg

Unit of Social Ecology, Université Libre de Bruxelles,

Bld du Triomphe, B-1050 Bruxelles, Belgium

\section{S. Beshers}

Department of Entomology,

University of Illinois at Urbana-Champaign,

320 Morrill Hall, 505 S. Goodwin Ave, Urbana, IL 61801, USA

\section{A. Dussutour ( $\square)$}

School of Biological Sciences, University of Sydney,

Heydon-Laurence Building A 08, Sydney, NSW 2006, Australia

e-mail: adussutour@usyd.edu.au reference to adjust their reach while cutting. Remarkably, despite the decrease in the foraging material brought to the nest per capita the colony was still able to improve its foraging performance by doubling the number of transporters. This study illustrates the flexibility of foraging behavior exhibited by an ant colony. It provides a rare example of insects finding an intelligent solution to a problem occurring in a foraging context, at both the individual and collective levels.

Keywords Leaf-cutting ants $\cdot$ Foraging behavior . Flexibility $\cdot$ Recruitment $\cdot$ Crowding $\cdot$ Learning

\section{Introduction}

The foraging behavior of social insects is highly flexible because it depends both on individual and collective decisions (Camazine et al. 2001; Detrain et al. 1999; Detrain and Deneubourg 2006). This flexibility allows a social insect colony to rapidly adjust its foraging strategy to changes occurring in the environment (Seeley 1995; Gordon 1996). Decisions at the individual level are based on cognitive processes that can be relatively simple or that can reach high level of sophistication as in honeybees (Giurfa 2003, 2007; Menzel and Giurfa 2006). Collective decisions on the other hand are based on self-organized processes and they emerge from the sharing of local and partial information between individuals through direct or indirect communication (Bonabeau et al. 1997). A social insect colony functions as a cognitive distributed system where there is no centralization of information. Since the term intelligence is sometimes used to define the capacity for an organism to solve problems arising from novel environmental situations, this flexibility has been termed "swarm intelligence" 
by some authors (Bonabeau et al. 1999; Garnier et al. 2007).

Most studies that have investigated the flexibility of foraging behavior in social insects have dealt with the changes occurring in the availability of food sources, e.g., the removal of a food source by competitors, or the discovery by scout workers of a new and more profitable food source (Pasteels et al. 1987; de Biseau et al. 1991; Seeley et al. 1991; Beckers et al. 1993; review in Detrain et al. 1999). Foraging behavior, however, can be potentially affected by other types of environmental modifications. For example, a change in the physical properties of the environment can affect the foraging behavior of ants both at the individual level, by making the access to a food source more difficult, and at the collective level, by altering the properties of the recruitment pheromone (Detrain et al. 2001). In this paper we investigate the flexibility of individual and collective foraging behavior in leaf-cutting ants following a change in the physical properties of the environment.

Leaf-cutting ants are considered to be the dominant herbivores in the Neotropics (Hölldobler and Wilson 1990). They cut vegetation into small fragments that they transport to their nest. This material is not directly consumed by the workers, but is incorporated into a fungus on which they feed (Weber 1972). Numerous studies have been devoted to the individual rules used by workers to decide on the size of the leaf fragments they cut (see, e.g., Roces 1990; Wetterer 1990, 1991; Burd 1995, 1996). Most of them are in agreement with the size-matching hypothesis, i.e., they find a good correlation between the size of the leaf fragment that is transported and the mass or the size of the foragers (see, e.g., Lutz 1929; Cherrett 1972; Wetterer 1991; Burd 1995). According to Weber (1972) this could result, in part, from the geometric method employed for leaf cutting: workers anchor on the leaf edge by their hind legs and pivot around their body while cutting. The load size would therefore be directly determined by a fixed reach which depends exclusively on the body size of the workers. Other studies have reported an absence of size-matching, suggesting that there is some flexibility in cutting, and that workers may vary the sizes of leaf fragments in response to other factors. For instance, for an ant of a given size, numerous authors have found that the size of the harvested fragment can be explained in part by leaf density (leaf mass/leaf area) (Cherrett 1972; Rudolph and Loudon 1986; Roces and Hölldobler 1994; Burd 1995), leaf toughness (Nichols-Orians and Schultz 1989) or leaf thickness (Van Breda and Stradling 1994).

The size of the fragments cut by leaf-cutting ants can also depend on factors that are not directly related to the leaf characteristics. For example, for an ant of a given size, workers of the leaf-cutting ant Acromyrmex lundi cut fragments of increasing size when they collect food far from the nest (Roces 1990), while those of Atta cephalotes cut smaller fragments when they have been food-deprived, or when they are confronted with unfamiliar leaves (Roces and Hölldobler 1994). In all these cases the size of the fragments does not simply depend on the mechanical properties of the leaf. Ants actually choose to cut fragments of a certain size. This probably requires a template that they can use as a reference to adjust their reach while cutting. In this paper, we investigate whether ants are able to adjust both the size and shape of the fragments they cut as a function of another external factor, namely the physical structure of the environment. A previous study by Prado (1973) has shown that leaf-cutting ants are able to re-cut the fragments they have cut in order to adjust their size to the diameter of a hole $(\emptyset 5 \mathrm{~mm})$ they have to go through in order to reach their nest. Unfortunately, however, no quantitative data are available from this study and the difference in fragment size before and after the passage of the hole remains unknown. Here, we investigate whether ants are able to adjust both the size and the shape of the fragments they cut when a height constraint is placed over part of the trail linking their nest to the foraging area where they collect foraging material. We also studied the consequence of the introduction of this physical constraint at the collective level, by measuring the flow of laden and unladen workers on the trail before and after the introduction of the constraint.

\section{Materials and methods}

Species studied and rearing condition

We worked with the leaf-cutting ant Atta colombica, a species that uses mass recruitment through scent trails to exploit abundant food sources (Wirth et al. 2003). We used an experimental colony, which consisted of one queen, brood, about 20,000 workers, and approximately 11,000 $\mathrm{cm}^{3}$ of fungus distributed among four clear plastic nest boxes $(W \times L \times H: 12 \times 23 \times 10 \mathrm{~cm})$. The nest boxes were kept in a plastic tray $(W \times L \times H: 40 \times 60 \times 15 \mathrm{~cm})$ whose walls were coated with Fluon ${ }^{\circledR}$ to prevent ants from escaping. The nests were regularly moistened and the colony was kept at room temperature $\left(30 \pm 1{ }^{\circ} \mathrm{C}\right)$ with a $12: 12$ L/D photoperiod. We supplied the colony with leaves of Malus coccinela four times a day (8:00 a.m., 12:00 a.m., 4:00 p.m. and 8:00 p.m.). The leaves were placed in a plastic tray $(W \times L \times H: 40 \times 60 \times 15 \mathrm{~cm})$ which was used as a foraging area and was linked to the colony by a plastic bridge $300 \mathrm{~cm}$ long and $5 \mathrm{~cm}$ wide. In the experiments this bridge was removed and replaced by a new bridge $300 \mathrm{~cm}$ long and $5 \mathrm{~cm}$ wide, which either remained uncovered (control bridge) or was partially covered with a transparent plastic roof $(W \times L: 5 \times 10 \mathrm{~cm})$ placed $1 \mathrm{~cm}$ above the 
bridge and $5 \mathrm{~cm}$ before the end of it at the level of the food source (Fig. 1).

\section{Experimental procedure}

Because the removal of the marked bridge and its replacement by a new unmarked bridge was generally followed by a sharp decrease in ant traffic, a period of $24 \mathrm{~h}$ was allowed before starting an experiment and measuring the effect of bridge change on the characteristics of the traffic. One and half hours before the start of an experiment, the colony was deprived of foraging material by removal of all leaves remaining in the foraging area. Foraging material was placed again in the foraging area at the start of the experiment. This material consisted of 32 pieces of $6 \times 6 \mathrm{~cm}$ Parafilm ${ }^{\circledR}$ film and 32 leaves of Malus coccinela (generally $6 \times 4 \mathrm{~cm}$ ). The size of the fragments cut by leaf-cutting ants is known to be influenced by the physical and chemical properties of the leaves they collect (see, e.g., Burd 1995). Using Parafilm ${ }^{\circledR}$ thus allowed us to work with homogeneous food material (Roces and Núñez 1993; Van Breda and Stradling 1994). The pieces of Parafilm ${ }^{\circledR}$ that were used had previously been soaked for $24 \mathrm{~h}$ in a solution of apple juice $(900 \mathrm{cl})$ and $70 \%$ alcohol $(100 \mathrm{cl})$ in which 30 Malus coccinela leaves had been crushed. We offered M. coccinella leaves to the ants during the experiments because foraging activity was poorly stimulated by the pieces of Parafilm ${ }^{\circledR}$. This also prevented an accumulation of Parafilm ${ }^{\circledR}$ fragments on the fungus.

To minimize crowding effects on the foraging material, the pieces of Parafilm ${ }^{\circledR}$ and the leaves, rather than being placed directly on the ground, were hung from the branches of 16 artificial trees ( 2 leaves and 2 pieces of Parafilm ${ }^{\circledR}$ on each tree). Ants did not appear to be disturbed by the artificial texture of the Parafilm ${ }^{\circledR}$.

Twelve replicates of the experiment were achieved with each type of bridge (control-uncovered bridge- and experimental-covered bridge). In all replicates, the traffic on the bridge was filmed from above and at the center of the bridge for $60 \mathrm{~min}$ with a SONY Digital Handycam DCR VX 2000E camera.

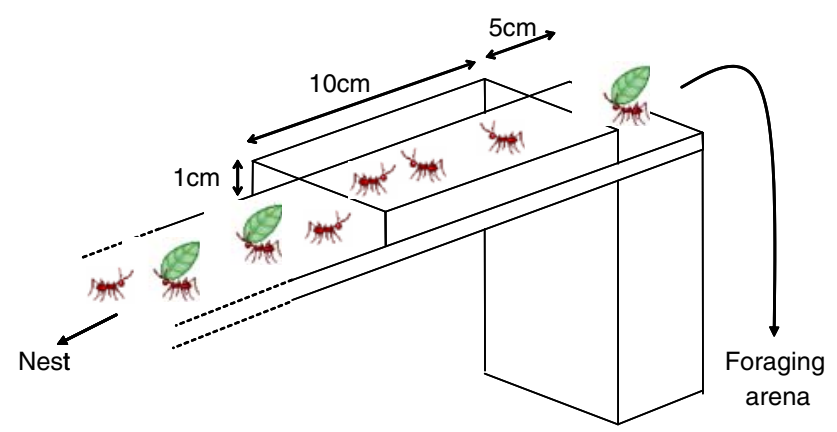

Fig. 1 Covered bridge used in the experiments
Data collection and analysis

\section{Effects of the roof on the flow of laden ants}

To measure foraging efficiency, we measured the total flow of workers (laden or unladen) on the bridge, the flow of laden workers only, and the probability that a worker would make a U-turn while on the covered part of the bridge. We counted, for each interval of 1 minute of each replicate, the number of laden (with a leaf fragment or a piece of Parafilm ${ }^{\circledR}$ ) and unladen ants traveling in both directions. Counting began when the first laden ant reached the nest. For the control bridge, ants were counted across a marked point in the middle of the bridge. For the experimental bridge ants were counted before and after the covered part of the bridge.

We used a two-way ANOVA with repeated measures on time to test for the effect of bridge type and time interval on the total flow of workers (laden or unladen) and on the flow of laden workers only. Moreover, to assess the rate of Uturns at the level of the roof on the experimental bridge we compared for each replicate of the experiment the flow of ants before and after the covered part with an ANOVA with repeated measures on time. In addition, for one replicate 200 laden ants were individually tracked while crossing the covered part of the bridge in order to evaluate the U-turn probability. Tracking began when the first laden ant began to cross the covered part of the bridge.

\section{Effects of the roof on travel duration}

For the two types of bridges we measured on a single replicate the travel duration for a sample of 60 laden and 200 unladen ants traveling to the nest on a $10-\mathrm{cm}$ section at the center of the control bridge and under the roof for the experimental bridge. The durations were measured from the time stamp of the video frames, allowing a precision of $1 /$ $25=0.04 \mathrm{~s}$. The measures began $15 \mathrm{~min}$ after the beginning of the experiment.

\section{Effects of the roof on the size distribution of laden ants}

In leaf-cutting ants of the genus Atta, the tasks performed by the workers on the trails are strongly correlated with their size (Stradling 1978; Wilson 1980). In order to investigate whether in our experiments forager size distribution on the trails was affected by the presence of the roof, we collected a sample of unladen ants on a single replicate for each bridge ( $N=263$ and 329 for the control and experimental bridge, respectively). These ants were randomly collected within an interval of $5 \mathrm{~min}$, starting $30 \mathrm{~min}$ after the beginning of the replicate. During the whole duration of each replicate we also collected a sample of approximately 
30 ants loaded with a fragment of Parafilm ${ }^{\circledR}$, as soon as they had traveled $2 \mathrm{~cm}$ onto the bridge from the foraging area for the control bridge and as soon as they had crossed the covered part for the experimental bridge. The Parafilm ${ }^{\circledR}$ fragment carried by each laden ant was collected and placed in an individual Eppendorf ${ }^{\circledR}$ and stored at $4{ }^{\circ} \mathrm{C}$. Over all replicates, a total of 261 and 342 laden ants were collected for the control and experimental bridge, respectively. Leaf-cutting ants often pick up leaf fragments that are either dropped on the ground by other ants (Anderson and Jadin 2001; Hart and Ratnieks 2001) or directly transferred from one individual to the other (Fowler and Robinson 1979; Hubbell et al. 1980; Anderson and Jadin 2001). Therefore, to ensure that the fragments had been cut by the workers we collected, the ants were followed from the moment they had completed their cut in the foraging area.

The maximal headwidth of unladen and laden ants was then measured to the nearest $0.05 \mathrm{~mm}$ under a dissecting microscope equipped with an ocular micrometer (Wilson 1980; Feener et al. 1988). We used a Kolmogorov-Smirnov test to compare the ant size distribution between the two types of bridges.

\section{Effects of the roof on load size and shape}

The area of the fragments collected was measured from digitized images obtained by scanning them at $75 \mathrm{dpi}$, allowing a resolution of approximately $0.1 \mathrm{~mm}^{2}$.

We used a multiple regression analysis to study the effect of headwidth and bridge type (control/experimental) on the size of the Parafilm ${ }^{\circledR}$ fragments collected. The equation of the model was the following:

Fragment area $=$ Constant $+b_{1}$ headwidth $+b_{2}$ bridge type $+b_{3}$ (interaction between headwidth and bridge type).

For each Parafilm fragment scanned, we then computed the ratio between the highest width and the highest length: $W / L$. The highest length corresponds to the first major axis of the fragment and is determined first. The highest width corresponds to the second major axis of the fragment, perpendicular to the first one. If the ratio is close to 1 the shape of the fragment can be considered as "compact", while if it is close to 0 the shape can be considered as lengthened. We used a Student $t$ test for independent samples to study the effect of bridge type on the ratio $W / L$.

\section{Effects of the roof on interaction rate}

For the two types of bridges we counted on a single replicate the number of encounters occurring per ant for a sample of 60 laden and 60 unladen ants traveling to the nest on a $10-\mathrm{cm}$ section at the center of the control bridge and under the roof for the experimental bridge. An encounter was considered each time an ant passed another one in the opposite direction, irrespective of whether a physical contact occurred between the ants. Encounters with or without physical contact were distinguished. The probability of being contacted during an interaction was estimated by regressing the number of encounters with physical contact on the total number of encounters with or without contact. Our objective was to assess specifically the probability for an outbound ant to contact a laden ant returning to the nest. However, because the traffic of laden ants on the bridge was relatively low, we found it more suitable to consider nestbound instead of outbound ants. As the traffic on the bridge had already reached a steady state when we began counting, the outbound and nestbound flows of workers were approximately equal. In this condition, the probability for an outbound (hence unladen) ant to contact a nestbound laden (or unladen) ant was the same as that of a nestbound laden (or unladen) ant to contact an outbound ant.

We used a multiple regression analysis to investigate the effect of bridge type and load carriage on the probability of being physically contacted during an encounter.

All statistical tests were conducted with SPSS for Windows (version 11, SPSS, Chicago, USA). For each multiple regression analysis, the continuous variables were centered on their mean and the categorical variables were coded as scalar numbers centered on zero. This procedure is recommended because it reduces the covariation between linear variables and their interaction terms (Aiken and West 1991). Following Engqvist's (2005) recommendation, all non significant interaction terms between the variables of the analysis were removed from the model.

\section{Results}

Effects of the roof on the flow of laden ants

The traffic volume was not significantly affected by the presence of a roof (Fig. 2a, two-way ANOVA with repeated measures on time interval: bridge type effect, $F_{1,22}$ $=1.54, P=0.229, \eta_{p}{ }^{2}=0.072$ ). On the other hand, the number of laden ants was three times as high on the covered bridge as on the uncovered bridge (Fig. $2 \mathrm{~b}, F_{1,22}=80.72, P$ $\left.<0.001, \eta_{p}{ }^{2}=0.801\right)$. The rate of fragment return to the nest was thus notably higher on the covered bridge than on the uncovered bridge.

The recruitment dynamics were not influenced by the presence of the roof (ANOVA: interaction bridge type $\times$ time, $F_{59,22}=1.18, P=0.290, \eta_{p}{ }^{2}=0.056$ and $F_{59,22}=1.82$, $P=0.191, \eta_{p}{ }^{2}=0.084$ for the total flow of ants and the flow of laden ants, respectively). The total flow of ants remained stable during the whole duration of the replicates for both bridges while on the covered bridge the flow of laden ants slightly increased during the first $20 \mathrm{~min}$ of the replicates 

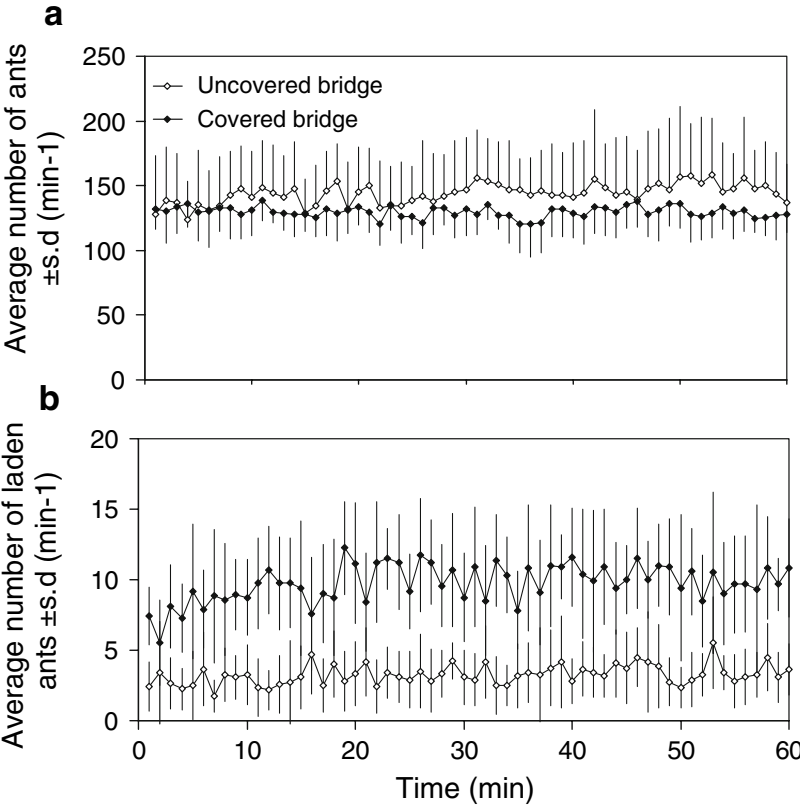

Fig. 2 Average number of ants per minute crossing the control (uncovered) or the experimental (covered) bridge in both directions. a Laden and unladen ants, $\mathbf{b}$ laden ants only. $N=12$ replicates of the experiment for each bridge

(ANOVA: time effect $F_{59,22}=2.196, \eta_{p}^{2}=0.099, P=$ $0.013)$.

The flow of laden ants was not significantly different before and after the covered part of the experimental bridge (ANOVA: counting site effect $F_{1,22}=0.132, P=0.720$, mean \pm SE $10.25 \pm 0.58$ and $9.9 \pm 0.67$ ant $\min ^{-1}$ before and after the covered part of the bridge, respectively) throughout the whole duration of the experiment (ANOVA: interaction counting site $\mathrm{x}$ time effect, $F_{59,22}=0.751, P=$ 0.918). Moreover only a single ant out of the 200 ants that were followed made a U-turn while crossing the covered part of the bridge. This means that the movement of the ants was not hampered by the roof and that they were able to cross the covered part of the bridge with their load.

Effects of the roof on travel duration

Travel duration was significantly affected by the presence of the roof on the bridge (two way ANOVA, bridge effect: $F_{1,517}=163.06 P<0.001$, Fig. 3). Ant progression was slower under the roof. Laden ants walked more slowly than unladen ones (load effect: $F_{1,517}=138.93 P<0.001$, Fig. 3) and this difference was essentially due to the presence of a roof (interaction between bridge type and load: $F_{1,517}=$ $22.36 P<0.001$, Fig. 3). The reduction in speed could be due to friction of the leaf fragment on the roof or to the fact that laden ants had to adopt a particular posture that hindered their locomotory behavior while walking under the roof.

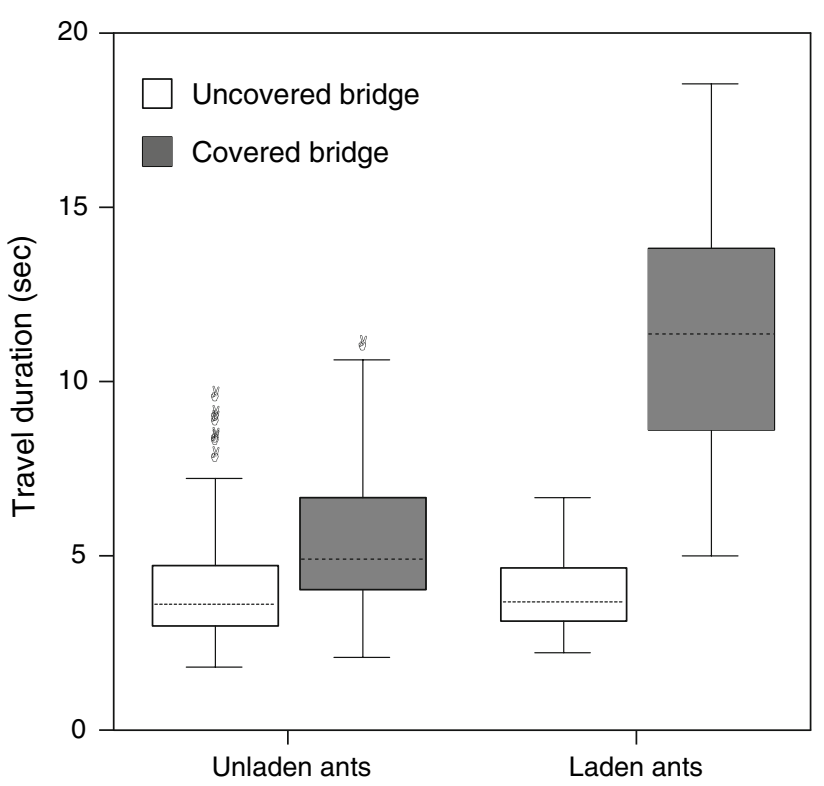

Fig. 3 Time spent crossing a 10-cm section for each bridge type $(N=$ 260 ants for each bridge type) and each category of ants (laden $N=120$ and unladen $N=400$ ). The dotted lines within the box plots represent the median; the lower and upper boundaries of the boxes represent, respectively, the 25 th and 75 th percentiles, while the whiskers extend to smallest and largest values within 1.5 box lengths. The open circles represent the outliers

Effects of the roof on the size distributions of laden ants

There was a weak significant difference between the size distribution of unladen ants on the two bridges (Fig. 4a; median headwidth: 1.50 and $1.56 \mathrm{~mm}$ for the control and experimental bridge, respectively; $Z=1.562, P=0.016$ ). The size distribution of laden ants was significantly different between the two bridges (Fig. $4 \mathrm{~b}$; median headwidth: 1.74 and $1.64 \mathrm{~mm}$ for the control and experimental bridge, respectively; $Z=3.301, P<0.001)$. Finally, on both bridges, laden ants were on average bigger than unladen ones $Z=5.298, P<0.001$ and $Z=3.407, P<0.001$, for the control and experimental bridge, respectively).

\section{Effects of the roof on load size and load shape}

The regression model of the Parafilm ${ }^{\circledR}$ fragment area on headwidth across bridge type was significant (Fig. 5; ANOVA for the whole model: $F_{2,600}=117.64, P<$ 0.001 ). Yet, it accounted for only $28.2 \%$ of the variance, showing that a great part of the variation in the size of the fragments remained unexplained. Since the interaction term between headwidth and bridge type was not significant $\left(b_{3}=8.734, t_{599}=1.793, P=0.073\right)$ it was removed from the model. The analysis shows that head-width and fragment area were positively correlated for the two 

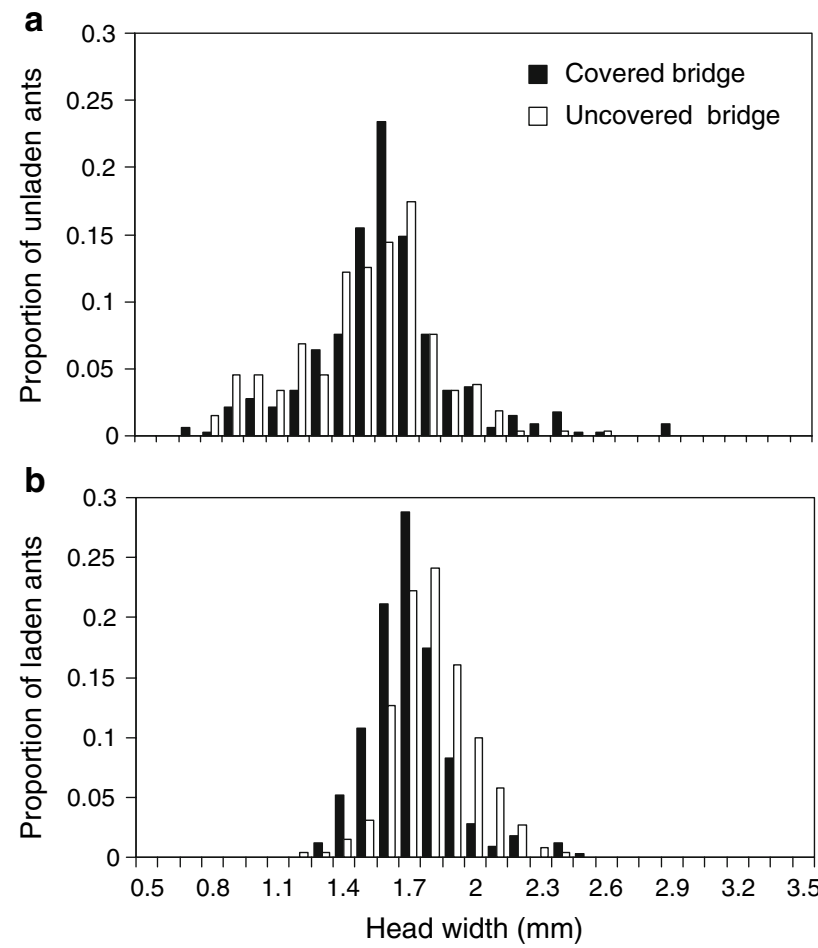

Fig. 4 Headwidth frequency distribution for a unladen ants $(N=263$ and 329 for the uncovered and covered bridge, respectively), b laden ants $(N=261$ and $N=342$ for the uncovered and covered bridge, respectively)

types of bridges $\quad\left(b_{1}=40.49, t_{600}=8.385, P<0.001\right)$, i.e., bigger ants cut larger fragments. Most importantly, keeping the size of the ants constant, the presence of a roof had an effect on the size of the Parafilm ${ }^{\circledR}$ fragments cut and transported by the foragers $\left(b_{2}=9.43, t_{600}=\right.$ $10.29, P<0.001)$. Ants cut smaller fragments when they had to travel back to the nest on a bridge partly covered (Student $t$ test: $t_{703}=12.162, P<0.001$; mean \pm SE: $65.37 \pm 1.78 \mathrm{~mm}^{2}$ and $42.59 \pm 0.91 \mathrm{~mm}^{2}$ for the uncovered and covered bridge, respectively). There was no adjustment of the fragment size at the contact of the roof because we never observed an ant re-cutting a leaf fragment at the entrance of the covered part of the bridge. Moreover, as mentioned before, there were practically no U-turns under the covered part of the bridge. Consequently, the roof did not act as a sorter to calibrate the size of the leaf fragments.

The presence of a roof had an effect on the ratio $W / L$ of the Parafilm ${ }^{\circledR}$ fragments cut and transported by the foragers $\left(t_{521}=-4.54, P<0.001\right.$, mean ratio: $0.71 \pm \mathrm{SD} 0.13$ and $0.78 \pm \mathrm{SD} 0.14$ for the control and the experimental bridge, respectively). Therefore, the shape of the fragments brought back to the nest was significantly different between the two bridges (Fig. 6): ants cut smaller and "compacter" fragments when the bridge was covered.

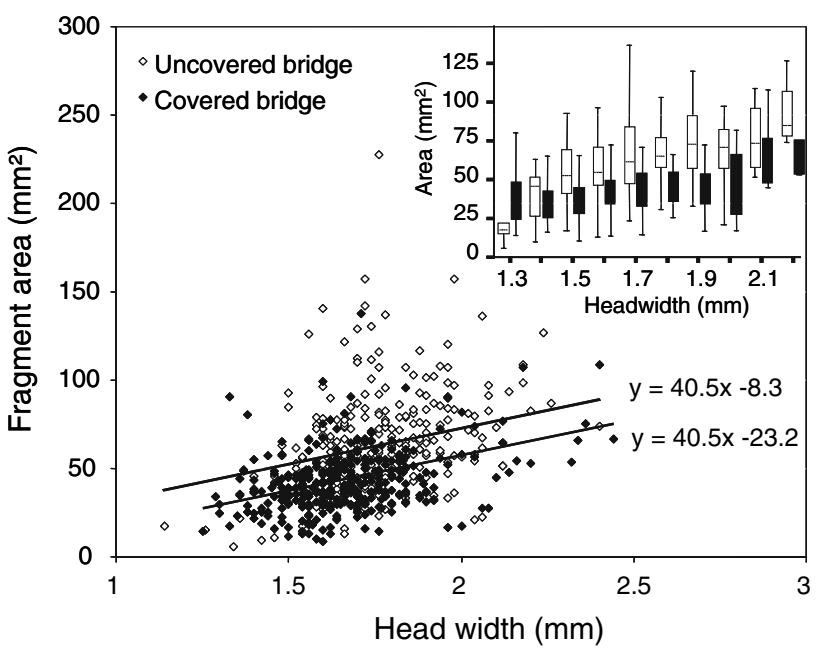

Fig. 5 Relationship between headwidth and fragment area $(N=261$ and 342 for the uncovered and covered bridge, respectively). The inset shows mean fragment area for each headwidth class. The horizontal lines within the box plots represents the median, the lower and upper boundaries of the boxes represent, respectively, the 25 th and 75 th percentiles, while the whiskers extend to the smallest and largest values within 1.5 box lengths

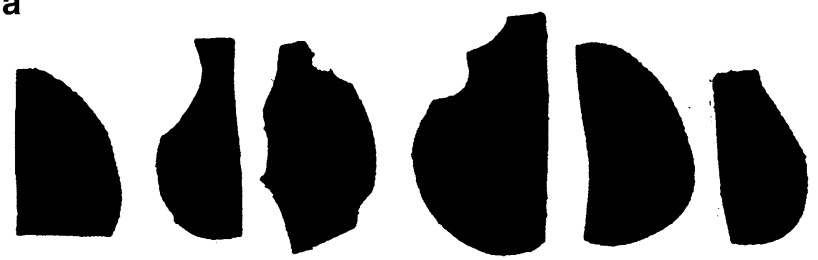

b

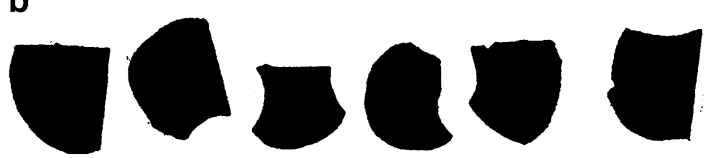

Fig. 6 Sample of leaf fragments carried by ants on a the uncovered bridge and $\mathbf{b}$ the covered bridge

\section{Effects of the roof on interaction rate}

The regression model of the effect of bridge type and load carriage (laden or unladen ants) on the probability of being contacted was significant (Table 1; Fig. 7; ANOVA for the whole model: $\left.F_{7,239}=141.091, P<0.001\right)$ and accounted for $86.7 \%$ of the variance. Since the interaction terms between ant category and number of encounters and that between number of encounters, bridge type and ant category were not significant $\left(b=-0.002, t_{238}=-0.25, P=\right.$ $0.801 b=0.006, t_{238}=0.66, P=0.508$, respectively) they were removed from the model. The model indicates a significant effect of the number of encounters and bridge type, as well as the interaction between these two variables (Table 1). The number of contacts was not significantly 
Table 1 Multiple regression analyses testing the relationship between the number of encounters with physical contact and the number of encounters with or without physical contact across bridge type and ant category (laden or unladen)

\begin{tabular}{lrrr}
\hline Independent variables & Unstandardized coefficients $b$ & Standardized coefficients $\beta$ & $t$ \\
\hline Constant & 2.763 & & $<$ value \\
Bridge type & -1.041 & -0.460 & $<0.001$ \\
Ant category & 0.069 & 0.030 & $<0.001$ \\
Number of encounters & 0.154 & 0.560 & 0.354 \\
Number of encounters $\times$ bridge type & -0.060 & -0.208 & $<.470$ \\
Bridge type $\times$ ant category & 0.175 & 0.077 & 16.265 \\
\hline
\end{tabular}

General equation for the multiple regression model: Number of contacts $=$ constant $+b_{1}$ bridge type $+b_{2}$ ant category $+b_{3}$ number of encounters $+b_{4}$ (number of encounters $\times$ bridge type $)+b_{5}$ (bridge type $\times$ ant category)

Fig. 7 Relationship between the number of encounters with contact and the total number of encounters per ant for a laden ants, $\mathbf{b}$ unladen ants. The slope of the lines corresponds to the probability for an ant traveling on the bridge to be contacted by another ant during an encounter $(N=60$ for each category of ants and each bridge type)
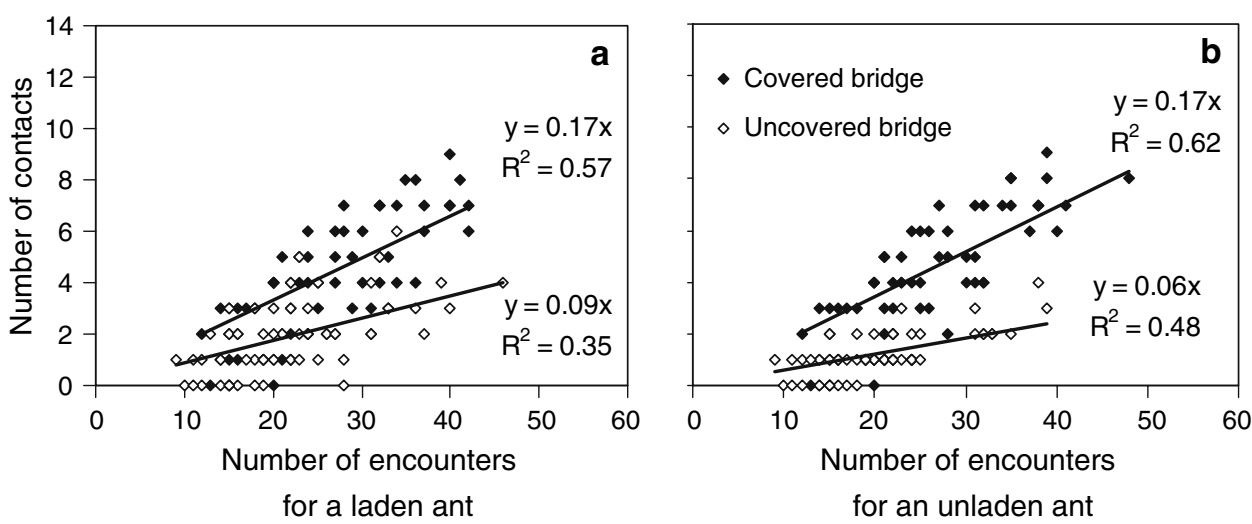

affected by the ant category (laden or unladen). Examination of the standardized regression coefficients shows that the main effect on the number of contacts was due to the number of encounters, followed by the presence of a roof and by the interaction between these two variables (Table 1).

The slopes of the four regression lines represented in Fig. 7 give the probability of physically contacting another ant during an encounter. This probability was significantly higher for the experimental (covered) bridge than for the control (uncovered) bridge, whether the workers were loaded or not (Table 1: interaction between bridge type and number of encounters).

Consequently, an ant coming from the nest and going to the food source had a probability about twice higher of contacting one or more laden ants on a covered bridge than on an uncovered bridge (mean $\pm \mathrm{CI}_{0,95}: 0.17 \pm 0.02$ vs. 0.09 \pm 0.01 , respectively).

Laden ants contacted a significantly higher number of ants on the covered bridge than on the uncovered one $\left(t_{118}=\right.$ 6.856, $P<0.001$, mean \pm SD: $4.40 \pm 2.46$ vs. $1.87 \pm 1.41)$.

\section{Discussion}

Our study demonstrates that a leaf-cutting ant colony is able to adapt to a change in the physical properties of the environment at two levels. At the individual level, ants cut smaller leaf fragments and of different shapes when a height constraint was placed on the way back to the nest. At the collective level, the total traffic remained unchanged in the presence of a height constraint, but the number of laden ants arriving to the nest was twice as large as in absence of a height constraint. Thus, the ants compensated for the reduction in load size by bringing more fragments to the nest. As a result, the rate of food return estimated from both fragment size and number, was higher in presence than in absence of a height constraint $\left(444 \mathrm{~mm}^{2} \min ^{-1}\right.$ vs. 212 $\mathrm{mm}^{2} \min ^{-1}$ ).

The size and shape of the leaf fragments were strongly modified after a height constraint was placed on the trail: independent of their size, forager ants cut smaller and rounder fragments in the presence of a roof on the trail than in its absence. The roof did not act as a mechanical sorter, because each ant from which a fragment was collected was followed from the moment it had finished cutting it until it reached the covered part of the bridge. Moreover, in contrast to Prado (1973), we never observed an ant cutting a fragment again in the foraging area once it had been separated from the leaf. The fact that ants cut smaller fragments was not due either to crowding on the foraging material and ants competing with each other for cutting sites, because under similar experimental conditions (same size of the foraging area, same volume of foraging material available) 
and with comparable values of the flow of laden ants on the bridge, we did not observe a reduction in the size of the fragments cut in absence of a height constraint (Dussutour et al. 2007). This shows that ants did adjust their cutting behavior after a height constraint was placed on the trail.

Four types of mechanisms could be proposed to explain the adjustment in fragment size observed. First, there could be a polyethism in the population of foragers of the same size class (Rissing 1981), with some ants cutting mostly big fragments and other small ones. Only the second group of ants could be active in the presence of the height constraint. However, this explanation does not hold because the number of laden ants was higher in the presence than in the absence of a height constraint. Therefore, the population of ants cutting small fragments in absence of the height constraint would not be enough to make up the population of cutting ants in the presence of the constraint. Second, the ants' motivational state to cut could be affected by the difficulties they face when crossing the covered part of the bridge. These difficulties would decrease the motivational state and this would translate in less time spent cutting and thus in smaller fragments cut. If anything however, for reasons related to the speed of information transfer, increased motivational state rather than decreased motivational state is responsible for the cutting of smaller size fragments in leaf-cutting ants (Roces and Hölldobler 1994). Third, crowding at the foraging area caused by the volume of traffic could explain the decrease in fragment size in the presence of the height constraint. Crowding could prevent some of the ants from approaching and cutting leaf and Parafilm fragments. Also, at high density, ants engaged in cutting may hinder one another. However, in our experiment the number of ants that reached the foraging area per unit of time did not differ significantly between the experimental and control conditions (mean \pm SD: $64.9 \pm 10.5$ vs. $69.01 \pm 9.67$ for the experimental and control bridge, respectively; two-way ANOVA with repeated measures on time interval: bridge type effect on the outbound flow, $F_{1,22}$ $=0.78, P=0.387, \eta_{p}{ }^{2}=0.038$ ) indicating the same level of crowding under the two conditions. Finally, the cutting of smaller size fragments could result from of a learning process. One could think of two different types of learning procedure. In the first type of procedure, ants could gauge the space under the height constraint and then decrease more or less rapidly the size of the fragments they cut until reaching the size that allows an unhindered progression under the roof. Ants could even cut to the right size after achieving only one trip to the nest. In fact, many insects are actually able to accurately assess and process dimensional information and subsequently adjust their behavior (e.g., nest material collection, signaling behavior) to the dimension measured without direct sensory feedback. For example, experimental manipulations of nest cell dimensions in the leaf-cutter bee Megachile tsurugensis show that these bees are able to measure the internal volume of a cell and then cut a disc from a leaf in the vegetation at the exact size corresponding to the volume measured (Kim 2007). Ants could thus measure the height of the constraint with the reach of their antennae during their first passage under the roof and subsequently cut fragments of the correct size. In the second type of learning procedure, ants could come upon the right solution by a process of trial and error, without direct measurement of the space under the height constraint. In other words, the solution would emerge spontaneously after several foraging trips. In fact, for an ant of a given size, there is enough variation in the size of the fragments cut (see Fig. 5) for the ants to come upon the right size, i.e., the size that allows an unhindered progression under the constraint, after several foraging trips. Once the right size has been found, the ant would use it as a template and would keep cutting fragments of this size. One could only distinguish between these two types of learning procedures by following ants individually and by measuring the size of the fragments they cut over successive foraging trips. If the first type of learning occurs, one would expect the number of foraging trips required to reach the correct fragment size to be fairly homogeneous across individuals. The variance of the number of foraging trips would be much higher if the second type of learning occurs. Further experiments would therefore be required to determine the mechanisms involved in the behavioral adjustment we observed.

The range of headwidth and fragment size we found in the experiments with the uncovered bridge is slightly smaller (Feener et al. 1988; Shutler and Mullie 1991; Burd 1995) or very similar (Howard 2001) to that found in field studies on Atta colombica. Moreover, the correlation between load size and maximal headwidth is similar to that found by other authors (Shutler and Mullie 1991; Burd 1996). This suggests that ants were not disturbed by the artificial texture of the Parafilm ${ }^{\circledR}$. We found that the size distribution of laden ants was a bit different between the two bridges: laden ants collected on the covered bridge had smaller headwith than those collected on the uncovered one. However, this difference cannot explain the reduction in the size of the fragments observed in the presence of a height constraint because, even when the size of the ants was kept constant, the fragments brought back to the nest were smaller in the experiments with the covered bridge. One possibility is that, because of morphological constraints, ants with the biggest headwidth that were collected on the uncovered bridge may not be able to cut fragments small enough to allow unhindered progression on the covered bridge. Consequently, they could simply stop cutting after some time. Nevertheless, the fact that most ants did reduce the size of the fragments they cut in the presence of 
a height constraint demonstrates that leaf-cutting ants exhibit some flexibility in their cutting behavior and that the size of the fragments is not as strongly constrained by their morphology as was previously thought (Weber 1972).

A striking result of our study is that the colony improved its foraging performance by increasing the number of transporters: the flow of laden ants was doubled in the presence of a height constraint. This difference cannot be due to an increase in the concentration of the trail pheromone on the covered bridge that could lead ants to cut more foraging material because the total flow of ants was comparable in presence or in absence of a height constraint. The most likely explanation is that in the presence of a height constraint, outbound workers could be more stimulated to cut and transport leaf fragments because of a higher rate of contact with inbound laden workers. In fact, whereas the rate of contact with nestbound unladen workers was approximately the same in presence or in absence of a height constraint, the rate of contact with nestbound laden workers was twice as high on the covered as on the uncovered bridge. This was due to the slower speed of laden ants while progressing under the height constraint. Physical contacts with laden ants could act as a sensitizing stimulus on outbound ants. As in other ant species (e.g., Lasius niger: Le Breton and Fourcassié 2004; species of the genus Acromyrmex: Lopes et al. 2004), what matters more here is probably the contact with the foraging material transported by returning ants than the mere contact with their body. Repeated contacts with laden ants may lower the response threshold of outbound ants to the presence of foraging material making them more likely to cut and transport leaves once they reached the foraging area. We observed a similar phenomenon in another study on leaf-cutting ants in which the density of workers on a trail was increased following a tenfold reduction of the width of the bridge (Dussutour et al. 2007).

The results presented here, together with the results of our previous study (Dussutour et al. 2007) provide a clear demonstration that under these laboratory conditions, leafcutting ants are able to modulate their foraging behavior in response to a change in trail conditions. We found changes in the number of workers recruited to a foraging area and the size distribution of the recruits, as well as the size and shape of cut leaf fragments. There may well be changes in other aspects of foraging behavior that would not be revealed by our observations and analyses. It could be that such adjustments are a normal part of leaf-cutting ant foraging if the ants encounter natural obstacles on their trails, or if they adjust to the different geometries of the leaves and branches of different species of trees or other plants. We are not aware of any field data that address these possibilities.

This study is yet another example of the flexibility of the foraging behavior exhibited by ants. It shows that ants can solve problems by making intricate adjustments of their foraging behavior, both at the individual and collective levels, not only as a function of their previous dietary experience (seed harvesting ants: Johnson 1991, Fewell and Harrison 1991; leaf-cutting ants: Roces and Núñez 1993, Roces and Hölldobler 1994, Howard et al. 1996), the satiety of their colony (Lasius niger : Mailleux et al. 2006; leaf-cutting ants: Roces and Hölldobler 1994) and the changes in food source availability and quality (review by Detrain et al. 1999), but also as a function of the changes occurring in the physical properties of their environment.

Acknowledgments We thank M. Gauthier and M. Giurfa for helpful discussions. A. D. was supported by a mobility fellowship (bourse de co-tutelle Belgique-France) from the French Ministry of Scientific Research and a fellowship (ATUPS) from Paul Sabatier University (Toulouse, France). J. L. D. is a research associate from the Belgian National Fund for Scientific Research.

\section{References}

Aiken LS, West SG (1991) Multiple regression: testing and interpreting interactions. Sage Publications, Newbury Park

Anderson C, Jadin JLV (2001) The adaptive benefit of leaf transfer in Atta colombica. Insect Soc 48:404-405

Beckers R, Goss S, Deneubourg J-L (1993) Modulation of trail laying in the ant Lasius niger (Hymenoptera: Formicidae) and its role in the collective selection of a food source. J Insect Behav 6:751759

Bonabeau E, Theraulaz G, Deneubourg J-L, Aron S, Camazine S (1997) Self-organization in social insects. Trends Ecol Evol 12:188-193

Bonabeau E, Dorigo M, Theraulaz G (1999) Swarm intelligencefrom natural to artificial systems. Oxford University Press, Oxford

Burd M (1995) Variable load size-ant size matching in leaf-cutting ants, Atta colombica (Hymenoptera: Formicidae). J Insect Behav 8:715-722

Burd M (1996) Foraging performance by Atta colombica, a leaf-cutting ant. Am Nat 148:597-612

Camazine S, Deneubourg J-L, Franks N, Sneyd J, Theraulaz G, Bonabeau E (2001) Self-organization in biological systems. Princeton University Press, Princeton

Cherrett JM (1972) Some factors involved in the selection of vegetable substrate by Atta cephalotes (L.) (Hymenoptera: Formicidae) in tropical rain forest. J Anim Ecol 41:647-660

de Biseau J-C, Deneubourg J-L, Pasteels J-M (1991) Collective flexibility during mass recruitment in the ant Myrmica sabuleti (Hymenoptera: Formicidae). Psyche 98:323-336

Detrain C, Deneubourg J-L, Pasteels J-M (1999) Decision-making in foraging by social insects. In: Detrain C, Deneubourg J-L, Pasteels J-M (eds) Information processing in social insects. Birkhäuser Verlag, Basel, pp 331-354

Detrain C, Deneubourg J-L (2006) Self-organized structures in a superorganism: do ants "behave" like molecules? Phys Life Rev $3: 162-187$

Detrain C, Natan C, Deneubourg J-L (2001) The influence of the physical environment on the self-organised foraging patterns of ants. Naturwissenschaften 88:171-174

Dussutour A, Beshers S, Deneubourg J-L, Fourcassié V (2007) Crowding increases foraging efficiency in the leaf-cutting ant Atta colombica. Insectes Soc 54:158-165 
Engqvist L (2005) The mistreatment of covariate interaction terms in linear model analyses of behavioural and evolutionary ecology studies. Anim Behav 70:967-971

Feener DH, Lighton JRB, Bartholomew GA (1988) Curvilinear allometry, energetics and foraging ecology: a comparison of leaf-cutting ants and army ants. Funct Ecol 2:509-520

Fewell JH, Harrison JF (1991) Flexible seed selection by individual harvester ants, Pogonomyrmex occidentalis. Behav Ecol Sociobiol 28:377-384

Fowler HG, Robinson SW (1979) Foraging by Atta sexdens (Formicidae: Attini): seasonal patterns, caste and efficiency. Ecol Entomol 4:239-247

Garnier S, Gautrais J, Theraulaz G (2007) The biological principles of swarm intelligence. Swarm Intell 1:3-31

Giurfa M (2003) Cognitive neuroethology: dissecting non-elemental learning in honeybee brain. Curr Opn Neurobiol 13:726-735

Giurfa M (2007) Behavioral and neural analysis of associative learning in the honeybee: a taste from the magic well. J comp Physiol A 193:801-824

Gordon DM (1996) The organization of work in social insect colonies. Nature 380:121-124

Hart AG, Ratnieks FLW (2001) Leaf caching in the leafcutting ant Atta colombica: organizational shift, task partitioning and making the best of a bad job. Anim Behav 62:227-234

Hölldobler B, Wilson EO (1990) The ants. Harvard University Press, Cambridge

Howard JJ (2001) Costs of trail construction and maintenance in the leaf-cutting ant Atta colombica. Behav Ecol Sociobiol 49:348356

Howard JJ, Henneman ML, Cronin G, Fox JA, Hormiga G (1996) Conditioning of scouts and recruits during foraging by a leaf-cutting ant, Atta colombica. Anim Behav 52:299-306

Hubbell SP, Johnson LK, Stanislav E, Wilson B, Fowler H (1980) Foraging by bucket-brigade in leaf-cutter ants. Biotropica 12:210 213

Kim J (2007) Disc size regulation in the brood cell building behavior of leaf-cutter bee, Megachile tsurugensis. Naturwissenschaften 94:981-990

Johnson RA (1991) Learning, memory, and foraging efficiency in two species of desert seed-harvester ants. Ecology 72:1408-1419

Le Breton J, Fourcassié V (2004) Information transfer during recruitment in the ant Lasius niger L. (Hymenoptera, Formicidae). Behav Ecol Sociobiol 55:242-250

Lopes JFS, Orti LCF, Camargo RS (2004) The influence of the scout upon the decision-making process of recruited workers in three Acromyrmex species (Formicidae: Attini). Behav Proc 67:471476

Lutz FE (1929) Observations on leaf-cutting ants. Am Mus Novit 388:1-21
Mailleux AC, Detrain C, Deneubourg J-L (2006) Starvation drives a threshold triggering communication. J Exp Biol 209:4224-4229

Menzel R, Giurfa M (2006) Dimensions of cognition in an insect, the honeybee. Behav Cogn Neurosc Rev 5:24-40

Nichols-Orians CM, Schultz JC (1989) Leaf thoughness affects leaf harvesting by the leaf cutter ant, Atta caphalotes (L.) (Hymenoptera: Formicidae). Biotropica 21:80-83

Pasteels J-M, Deneubourg J-L, Goss S (1987) From individual to collective behavior in social insects. Les Treilles Workshop, Basel

Prado L (1973) Le comportement de decoupage des feuilles chez Atta sexdens. Insect Soc 20:133-144

Rissing SW (1981) Foraging specializations of individual seed-harvester ants. Behav Ecol Sociobiol 9:149-152

Roces F (1990) Leaf-cutting ants cut fragment sizes in relation to the distance from the nest. Anim Behav 40:1181-1183

Roces F, Núñez JA (1993) Information about food quality influences load-size selection in recruited leaf-cutting ants. Anim Behav 45:135-143

Roces F, Hölldobler B (1994) Leaf density and a trade-off between load-size selection and reruitment behavior in the ant Atta cephalotes. Oecologia 97:1-8

Rudolph SG, Loudon C (1986) Load size selection by foraging leafcutter ants (Atta cephalotes). Ecol Entomol 11:401-410

Seeley TD (1995) The wisdom of the hive: the social physiology of honey bee. Harvard University Press, Cambridge

Seeley T, Camazine S, Sneyd J (1991) Collective decision-making in honey bees: how colonies choose among nectar sources. Behav Ecol Sociobiol 28:277-290

Shutler D, Mullie A (1991) Size-related foraging behaviour of the leafcutting ant Atta colombica. Can J Zool 69:1530-1533

Stradling DJ (1978) The influence of size on foraging in the ant, Atta cephalotes, and the effect of some plant defence mechanisms. J Anim Ecol 47:173-188

Van Breda JM, Stradling DJ (1994) Mechanisms affecting load size determination in Atta cephalotes L. (Hymenoptera, Formicidae). Insect Soc 41:423-434

Weber NA (1972) Gardening ants the attines. Memoirs of the American Philosophical Society, Philadelphia

Wetterer JK (1990) Load-size determination in the leaf-cutting ant, Atta cephalotes. Behav Ecol 1:95-101

Wetterer JK (1991) Source distance has no effect on load size in the leaf-cutting ant, Atta cephalotes. Psyche 98:355-359

Wilson EO (1980) Caste and division of labor in leaf-cutter ants (Hymenoptera: Formicidae: Atta). I. The overall pattern in Atta sexdens. Behav Ecol Sociobiol 7:143-156

Wirth R, Herz H, Ryel RJ, Beyschlag W, Hölldobler B (2003) The herbivory of leaf-cutting ants. A case study on Atta colombica in the Tropical Rainforest of Panama. Ecological studies. Springer, Heidelberg 